\title{
An investigation of copper corrosion inhibition in chloride solutions by benzo-hydroxamic acids
}

\author{
A. Shaban, ${ }^{*}$ E. Kálmán and J. Telegdi \\ Central Research Institute for Chemistry of the Hungarian Academy of Sciences, P.O. Box 17, \\ H-1525 Budapest, Hungary
}

(Received 30 October 1996; in revised form 15 December 1996)

\begin{abstract}
Benzo-hydroxamic acids (BHA) are investigated as potential copper corrosion inhibitors in chloride solution. The BHAs investigated were: $p$-chloro-benzo-hydroxamic ( $p$-Cl-BHA), o-chloro-benzohydroxamic acid (o-Cl-BHA), $p$-nitro-benzo-hydroxamic acid ( $p$-N-BHA) and $o$-methyl-benzo-hydroxamic acid (o-M-BHA). Electrochemical measurements, potentiostatic polarization and ac impedance spectroscopy were carried out to evaluate the inhibition effect of the investigated BHAs. An Electrochemical Quartz Crystal Microbalance (ECQM) was used to measure electrode corrosion and inhibitor adsorption or layer formation processes. A poorly soluble layer consisting of the inhibitor and copper corrosion products is proposed to account for the protective effect in chloride solutions. (C) 1997 Elsevier Science Ltd
\end{abstract}

Key words: copper corrosion inhibition, quartz crystal microbalance, benzo-hydroxamic acids.

\section{INTRODUCTION}

Copper and its alloys are applied extensively in marine environments due to their high corrosion resistance in harsh sea waters. In addition, copper dissolution in chloride solutions is very important in the electropolishing and electromachining industries. Due to those reasons attention has been focused on the behavior of copper in chloride solutions. Even if copper corrosion in near neutral aqueous solutions seems to be low, the damage from the corrosion products such as $\mathrm{Cu}^{2}+$ ions could be very harmful. In most cases of copper corrosion, an additive must be added to the environment in order to modify or hinder the reactions involved in the process. Theoretically, there are a great number of materials that could be applied as corrosion inhibitors for copper corrosion but only a few formulations have been thoroughly investigated. Azoles, specifically triazoles, have been intensively investigated as effective copper corrosion inhibitors [1-3]. Stricter environmental restrictions forced the need to develop a more environment friendly replacement to toxic inhibitors. Hydroxamic acids (HAs) are well known

\footnotetext{
*Author to whom correspondence should be addressed.
}

chelating agents for mono-, bi- and trivalent metal ions [4]. Previous investigations showed HA derivatives as potentially effective corrosion inhibitors for copper [5]. Despite all the research devoted $t o$ azoles and other additives as copper inhibitors, the exact mechanism by which inhibition takes place on the metal is still not well understood. When considering the copper inhibitors, most researchers had to include surface products, such as oxides and different salt products, in the mechanism of inhibitor actions $[1,2]$. This approach makes common sense from both theoretical and practical points of view. In most practical cases, inhibitors have to be applied on moreor-less preexisting oxide or salt layers. This further complicates the corrosion system by involving different processes. In the absence of different complexing agents in the corrosion medium, such as $\mathrm{Cl}^{-}$ions, anodic dissolution of copper proceeds in two steps [3]:

$$
\begin{gathered}
\mathrm{Cu} \Leftrightarrow \mathrm{Cu}^{+}+e^{-}, \\
\mathrm{Cu}^{+} \Leftrightarrow \mathrm{Cu}^{2+}+e^{-} .
\end{gathered}
$$

In neutral aqueous solutions, where oxygen is present, the overall reaction of anodic copper dissolution could proceed as follows: 


$$
\mathrm{Cu}+1 / 2 \mathrm{O}_{2}+\mathrm{H}_{2} \mathrm{O} \rightarrow \mathrm{Cu}^{2+}+2 \mathrm{OH}^{-} .
$$

When complexing agents, such as $\mathrm{Cl}^{-}$, are present in the corrosive aqueous medium, complex copper ions, such as $\mathrm{CuCl}_{2}^{-}$, must be considered. In the near-neutral $\mathrm{pH}$ range of oxygen-containing mediums, the anodic reactions (at least at the immersion time) are as follows:

$$
\begin{gathered}
\mathrm{Cu}+\mathrm{Cl}^{-} \Leftrightarrow \mathrm{CuCl}+e^{-}, \\
\mathrm{CuCl}+\mathrm{Cl}^{-} \rightarrow \mathrm{CuCl}_{2}^{-} .
\end{gathered}
$$

Mass transfer effects have been shown to be significant during the anodic dissolution of copper in chloride media with cuprous chloride complexes as the major product species. At chloride concentrations less than $1 \mathrm{M}$ the copper dissolution reaction rate is of a second order with respect to $\mathrm{Cl}^{-}$, indicating that in this $\mathrm{Cl}^{-}$concentration range $\mathrm{CuCl}_{2}^{-}$is the dominant cuprous species [2]. Several mechanisms involving reactions (4) and (5) and mass transfer of $\mathrm{CuCl}_{2}^{-}$from the electrode surface to the bulk solution have been suggested to explain the kinetics of copper dissolution in the apparent-Tafel region.

The suggested electrochemical mechanism of copper corrosion could be verified by investigations using different electrochemical and electrogravimetrical methods. Electrochemical potentiostatic polarization curves and electrochemical impedance spectroscopy measurements (EIS) were performed in order to evaluate the inhibition effect of the investigated benzo-hydroxamic acids (BHA) on copper corrosion in $\mathrm{NaCl}$ solution. The application of the electrochemical quartz crystal microbalance technique (ECQM) allows us to determine the corrosion rate and observe the adsorption behavior of the inhibitors on the copper electrode surface. When an alternating voltage is applied between two faces of a quartz crystal blade, the blade oscillates. The frequency of oscillation of a quartz crystal is highly sensitive to the mass supported by the two faces of the device. Ideally a sub-mono-molecular adsorbed layer can be detected. Jope et al. [6] utilized the ECQM in corrosion inhibition studies in aqueous solutions. Differences in the inhibitor adsorption or metal dissolution velocities and the film thickness can be monitored simultaneously [6, 7]. It is also possible to study the corrosion of different metal alloys by ECQM [8].

\section{EXPERIMENTAL}

\section{Chemicals and solutions}

Analytical reagent-grade $\mathrm{NaCl}$ was used in this investigation without any further purification. The aqueous solution of $\mathrm{NaCl}$ was prepared in doubly distilled water. Benzo-hydroxamic acids, which were synthesized from their appropriate carboxylic acid chloride and hydroxylamine, were purified by recrystallization [9]. Their purity was checked by elemental analysis and melting point determination. Experiments were performed on copper electrodes in $0.5 \mathrm{M} \mathrm{NaCl}$ aqueous solutions without and with the addition of $1 \mathrm{mM}$ of each BHA.

\section{Electrochemical measurements}

A three-electrode glass cell was used for the potentiostatic polarization measurements. The counter electrode (ce) was a platinum half cylindrical plate with an area of $90 \mathrm{~cm}^{2}$. The cell reference was a saturated calomel electrode (sce) and the measured potential was referred to this electrode. The working electrode was a copper rod of $99.99 \%$ purity and $9.5 \mathrm{~mm}$ diameter imbedded into epoxy resin. The electrode was polished successively with 800 and 1200-grade emery papers, washed with acetone, rinsed with distilled water, and immersed immediately into the cell containing the electrolyte solution. The electrode corrosion potential was monitored until the change was less than $5 \mathrm{mV} / 5 \mathrm{~min}$.

Measurements were performed at room temperature and with continuous stirring. A computer controlled Solartron Electrochemical Interface (Mod. 1286) was utilized to perform the polarization measurements. Starting from the corrosion potential, the applied potential was swept automatically to a value of $500 \mathrm{mV}$ in the anodic region using a scan rate of $15 \mathrm{mV} / \mathrm{min}$.

A rotating disk electrode assembly, with a $250 \mathrm{ml}$ three-electrode cell, and conditions similar to the previous ones, was applied for EIS measurements. The working electrode was a rotating copper disk of $99.99 \%$ purity and $0.2 \mathrm{~cm}^{2}$ area inserted in a Teflon sample holder. The electrode rotation speed was 500 r.p.m. A computer-driven Solartron ECI1286 and FRA-1250 instruments were used to perform the measurements. Data were collected at the corrosion potential in a frequency range between 0.01 and $10000 \mathrm{~Hz}$.

\section{Electrogravimetric method}

The quartz crystal used was an AT-cut disk of $12 \mathrm{~mm}$ diameter and of $10 \mathrm{MHz}$ nominal oscillation frequency. At both sides gold electrode was deposited over a thin layer of chromium for adhesion purposes. Copper was galvanostatically deposited from an acidic copper bath containing $0.5 \mathrm{M} \mathrm{CuSO}_{4}, 0.5 \mathrm{M}$ $\mathrm{H}_{2} \mathrm{SO}_{4}$ and $1 \mathrm{M} \mathrm{C}_{2} \mathrm{H}_{5} \mathrm{OH}[6,7]$. The freshly deposited copper electrode was washed thoroughly with distilled water. Then immediately the aggressive solution was added into the cell. Measurements were performed under open circuit potential conditions (ocp). An assembly which consisted of a Model PS205 Potentiostat/Galvanostat and a Model EQCN700 Electrochemical Quartz Crystal Nanobalance (ELCHEMA) was used for the measurements. The program wave-form was generated by VOLTSCAN Real-Time Data Acquisition System (Intellect 


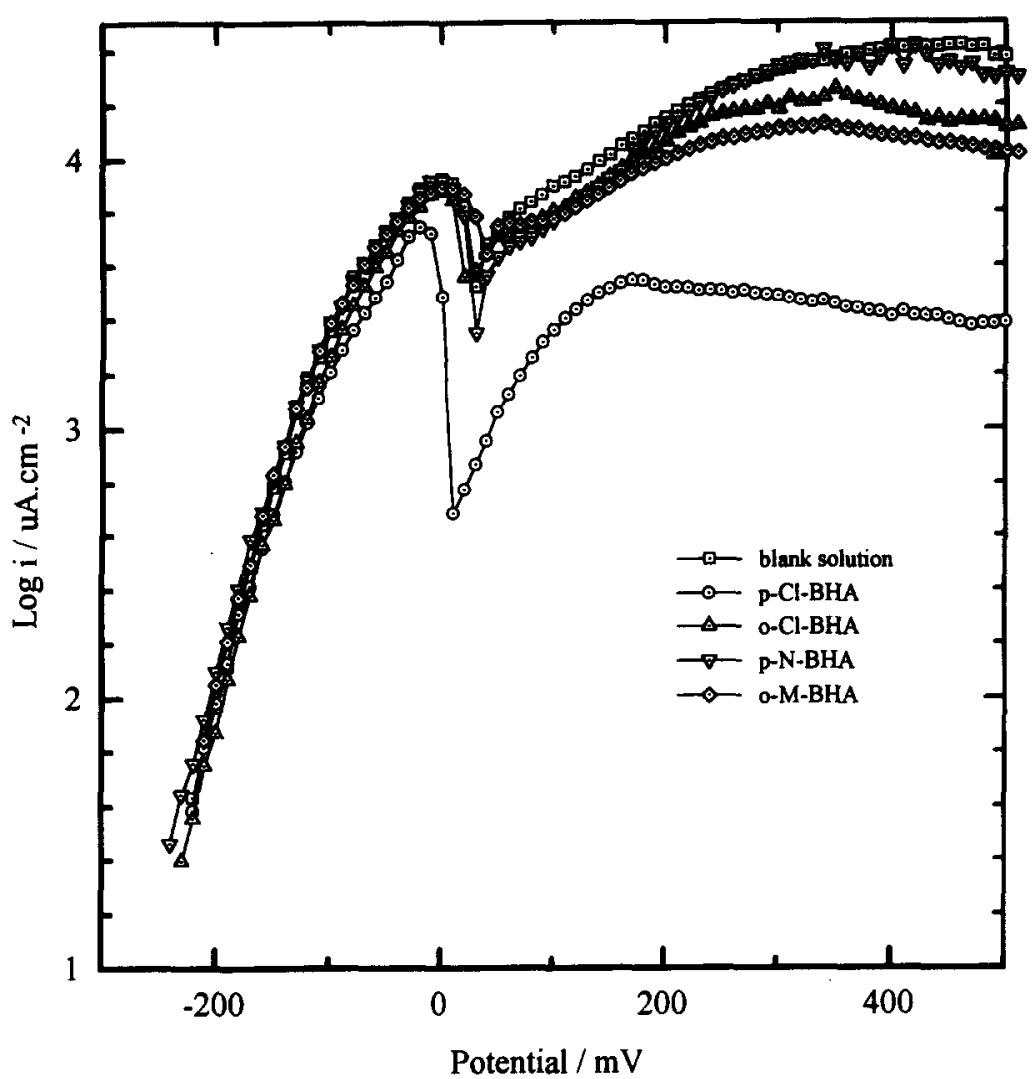

Fig. 1. Anodic polarization curyes of copper electrode in $0.5 \mathrm{M} \mathrm{NaCl}$ with the addition of $0.001 \mathrm{M}$ inhibitor.

Software). A sce and a platinum wire were used as reference and counter electrodes, respectively. Frequency changes which were automatically converted to mass changes on the working quartz electrode surface were registered as a function of time.

\section{RESULTS AND DISCUSSION}

\section{Electrochemical results}

The anodic polarization behavior of copper determined in $0.5 \mathrm{M} \mathrm{NaCl}$ solution without and with the addition of BHAs is illustrated by the curves in Fig. 1. All curves exhibited three distinct regions as previously reported by different researchers [1-3]: the Tafel region at lower over-potentials extending to a peak current density ( $i_{\text {peak }}$ ), then a region of decreasing currents until a minimum value $i_{\min }$ is reached and finally, a region of sudden increase in current density leading to a limiting value $\left(i_{\text {lim }}\right)$. In the apparent-Tafel region curves deviated slightly from the blank solution. The anodic slope $\left(\beta_{\mathrm{a}}\right)$ and $\left(i_{\text {peak }}\right)$ values for all curves are listed in Table 1. A Tafel region exists in the absence and in the presence of the added BHAs. However, the addition of the inhibitors to the corrosive medium shifted the polarization curves toward lower $i_{\mathrm{lim}}, i_{\min }$ and $i_{\text {peak }}$ values. The extent of the shift was maximal in the case of $p$-Cl-BHA. The curves almost were superimposed on each other between $i_{\text {peak }}$ and $i_{\text {min }}$ except for the $p$-Cl-BHA curve which was clearly shifted to a much lower $i_{\min }$ value. In the presence of $p-\mathrm{Cl}$ BHA $i_{\min }$ was much lower than the blank solution (Table 1). A decrease in current density was also observed at potentials higher than that correspond-

Table 1.

Corrosion inhibition parameters of $\mathrm{Cu}$ electrode in $0.5 \mathrm{M} \mathrm{NaCl}$ without and with the addition of different BHAs

\begin{tabular}{lcccc}
\hline Inhibitor & $\begin{array}{c}\beta_{\mathrm{a}} \\
(\mathrm{mV} / \mathrm{Dec})\end{array}$ & $\begin{array}{c}\left(i_{\text {peak }}\right) \\
\left(\mu \mathrm{A} / \mathrm{cm}^{2}\right)\end{array}$ & $\begin{array}{c}\left(i_{\text {min }}\right) \\
\left(\mu \mathrm{A} / \mathrm{cm}^{2}\right)\end{array}$ & $\begin{array}{c}\text { Polarization res. }\left(R_{\mathrm{p}}\right) \\
\left(\mathrm{k} \mathrm{ohm} \mathrm{cm}^{2}\right)\end{array}$ \\
\hline Blank & 65 & 8700 & 3675 & 3.5 \\
$p$-Cl-BHA & 82 & 5620 & 485 & 17.2 \\
$o$-Cl-BHA & 72 & 7820 & 3935 & 9.7 \\
$p$-N-BHA & 75 & 7780 & 2265 & 13.0 \\
$o$-M-BHA & 72 & 7940 & 4345 & 5.5 \\
\hline
\end{tabular}


(a)

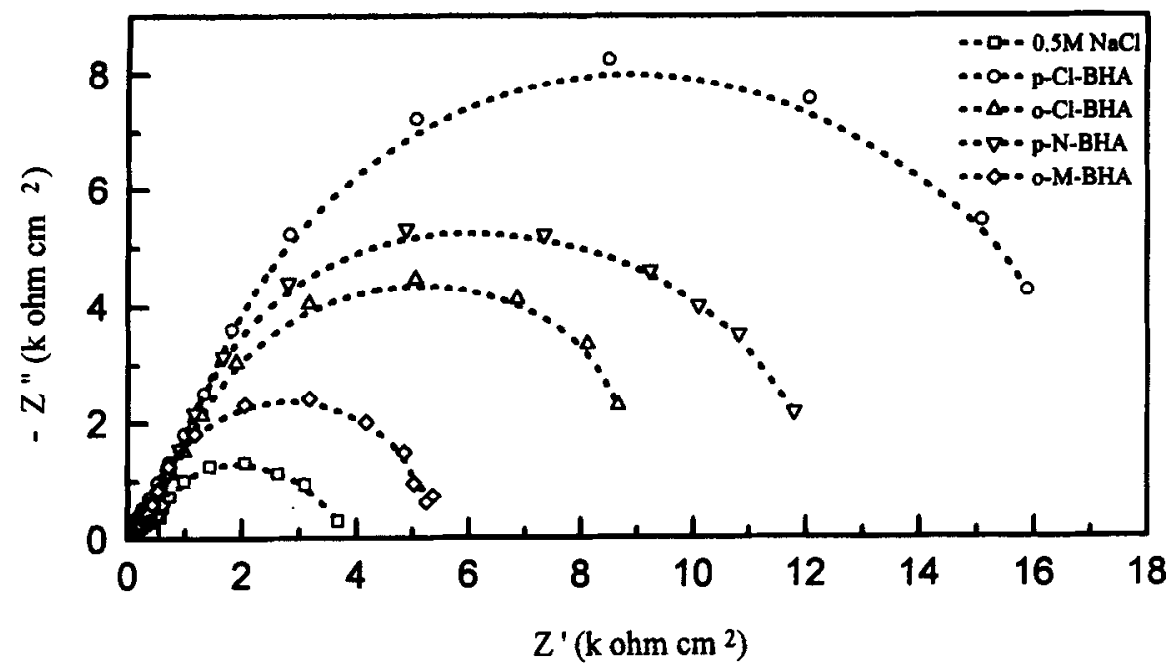

(b)

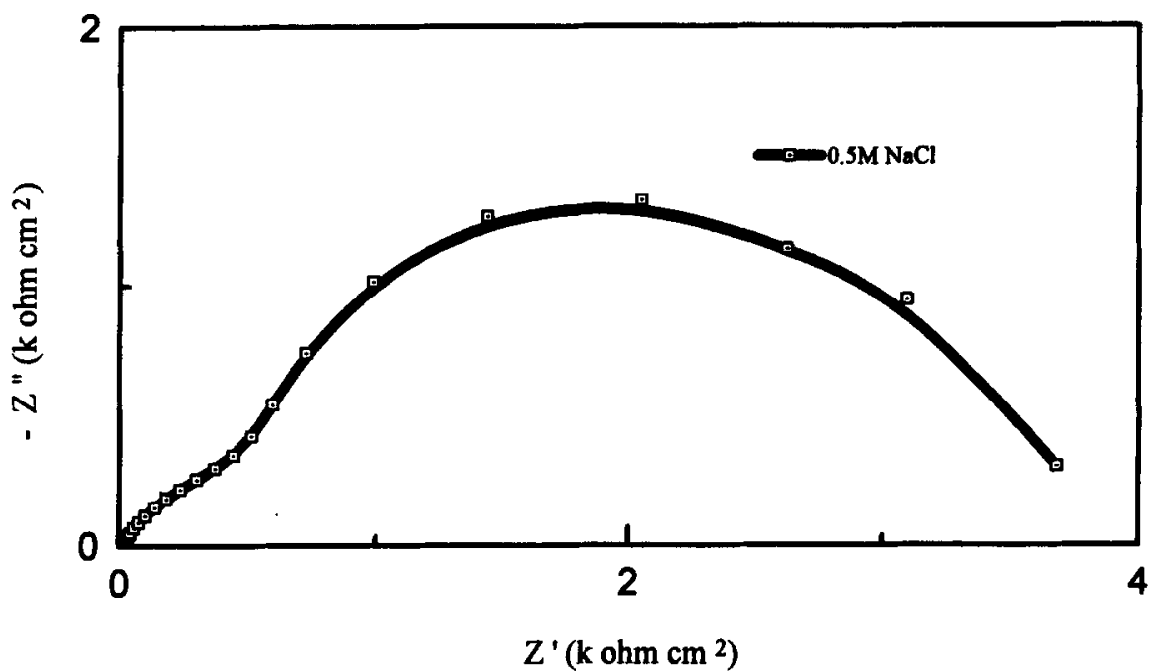

Fig. 2. (a) ac impedance Nyquist plots for copper electrode in $0.5 \mathrm{M} \mathrm{NaCl}$ with the addition of $0.001 \mathrm{M}$ inhibitor at the corrosion potential. (b) ac impedance Nyquist plots for copper electrode in $0.5 \mathrm{M} \mathrm{NaCl}$ (an illustration of the high frequency semi-circle).

ing to $i_{\min }$. The change in $i_{\text {lim }}$ was noticeable for all BHAs tested except for $p$-N-BHA.

The AC impedance results, obtained at the corrosion potential, are depicted as Nyquist plots in Fig. 2(a). As reported by Fiaud [1] and Mansfeld [10], two more-or-less poorly separated semi-circles are obtained and are characteristic of the anodic partial reaction involving mass transfer occurring through the $\mathrm{Cu}_{2} \mathrm{O}$ layer. The semi-circle at high frequency is due to the modulation of $\mathrm{CuCl}$ adsorbed at the electrode, as indicated by reactions 4 and 5 and illustrated in Fig. 2(b). The low frequency part of the curves represents the diffusion process at the electrode, due to $\mathrm{CuCl}_{2}^{-}$and other adsorbed materials. Data deviation was noticed at the low frequency region due to the instability of the electrode surface. The radius of the low frequency semi-circle represents the polarization resistance value $\left(R_{\mathrm{p}}\right)$.
The $R_{\mathrm{p}}$ values, listed in Table 1 , are used to estimate the corrosion inhibition effect. All investigated BHAs produced higher $R_{\mathrm{p}}$ values than the blank solution, indicating the formation of a protective layer on the electrode surface which hinders the anodic reactions. As could be seen from Fig. 2 and Table 1 , the order of inhibition effectiveness was $p$-Cl-BHA $>p$-N-BHA $>o$-Cl-BHA $>o-\mathrm{M}$-BHA.

\section{Electrogravimetrical results}

Figure 3 shows the results of ECQM experiments for the BHAs studied in $0.5 \mathrm{M} \mathrm{NaCl}$. The curves represent the change of mass on the electrode surface as a function of time. The decrease of mass, which can be calculated from the frequency increase, represents the material loss due to copper corrosion. The addition of $0.5 \mathrm{M} \mathrm{NaCl}$ solution shows the highest mass loss rate indicating a high 


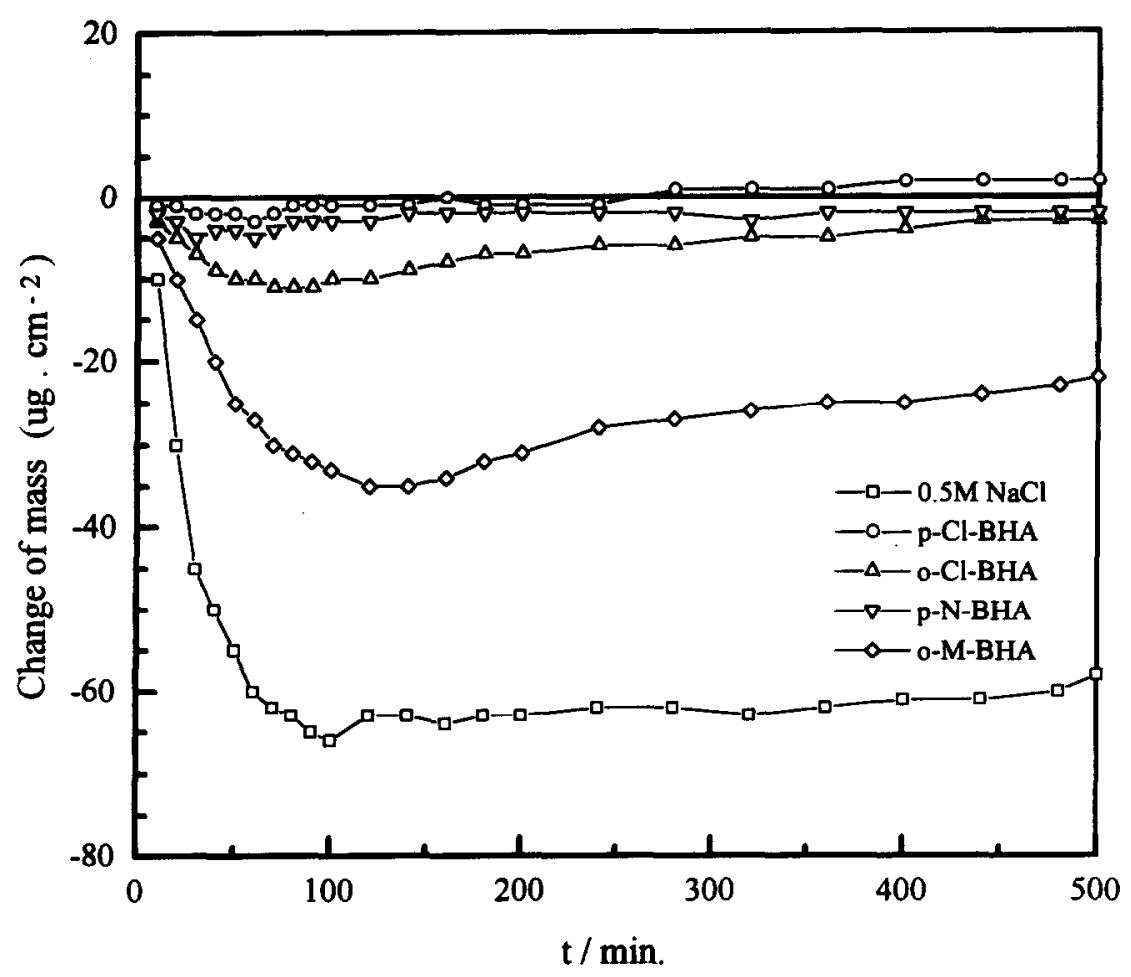

Fig. 3. Mass deviation of copper piezoelectrode in $0.5 \mathrm{M} \mathrm{NaCl}$ with the addition of $0.001 \mathrm{M}$ inhibitor at the ocp.

corrosion rate. Curves representing BHAs showed a region of sudden decrease of the electrode mass followed by a relaxed region where the apparent mass loss rate slightly changed. The addition of $p$-ClBHA produced the maximum protection against copper corrosion in $\mathrm{NaCl}$. At longer measuring time, when $p-\mathrm{Cl}-\mathrm{BHA}$ was added, the electrode mass increased due to inhibitor adsorption or complex formation processes taking place on the electrode surface. It is difficult to distinguish between the two processes. The addition of $p-\mathrm{N}-\mathrm{BHA}$ also decreased the mass loss noticeably. Figure 3 shows that the order of copper corrosion inhibition is in agreement with the previous electrochemical results. Figure 3 indicates that time is needed for the inhibitors adsorption onto the electrode surface. In most cases this effect took place after an hour of immersion time.

\section{CONCLUSIONS}

The inhibition effect of the investigated BHAs on copper corrosion in $0.5 \mathrm{M} \mathrm{NaCl}$ solution was studied and the behavior of the copper electrode was discussed. The most affective BHAs, of the investigated series, in controlling copper corrosion were $p$ Cl-BHA and $p$-N-BHA. A complex layer of the inhibitor and copper corrosion products, with low solubility, is proposed to account for the protective effect in chloride solutions. The exact structure of this layer (complex) needs further investigations. The in-situ ECQM method could be used to gather quick and vital information on the copper electrode behavior in near neutral aqueous chloride solutions. Its high sensitivity enables us to investigate even a mono-layer scale. A set back for this method is to distinguish between different processes taking place at the same time on the electrode surface.

\section{ACKNOWLEDGEMENTS}

This study was supported by the Hungarian National Research Fund (OTKA-T017626).

\section{REFERENCES}

1. C. Fiaud, 8th Eur. Symp. on Corrosion Inhibitors, Ann. Univ. Ferrara 2, 929 (1995).

2. H. P. Lee and K. Nobe, J. Electrochem. Sac. 133, 2035 (1986).

3. F. K. Crundwell, Electrochim. Acta 37, 2707 (1992)

4. B. Kurzak, W. Bal and H. Koslowski, J. Inorg. Biochem. 38, 91990.

5. A. Shaban, J. Telegdi and E. Kálmán, Progress in the Understanding and Prevention of Corrosion (Edited by J. M. Costa and A. D. Mercer). The Institute of Materials, London, Vol. 2, p. 916 (1993).

6. D. Jope, J. Sell, H. W. Pickering and K. G. Weil, J. Electrochem. Soc. 142, 2170 (1995).

7. A Shaban, E. Kálmán and J. Bacskai, 8th Eur. Symp. an Corrosion Inhibitors, Ann. Univ. Ferrara, 2, 951, (1995).

8. H. W. Pickering, K. G. Weil, personal communications.

9. C. R. Hauser and W. B. Renfrow, Jr., Org. Synth. Coll. Vol. II, 67 (1971).

10. F. Mansfeld, M. W. Kendig and S. Tsai, Corrosion 38, 570 (1982). 